\title{
Biofuels, Bioenergy, and Bioproducts from Sustainable Agricultural and Forest Crops
}

\author{
Michael D. Casler • Rob Mitchell • Jim Richardson • \\ Ronald S. Zalesny Jr.
}

Published online: 7 August 2009

(C) Springer Science + Business Media, LLC. 2009

Keywords Biomass · Crop improvement . Lignocellulosics · Productivity · Sustainability

This issue of BioEnergy Research highlights the Short Rotation Crops International Conference held in Bloomington, Minnesota in August 2008. This is the first special issue of BioEnergy Research, with several additional special issues planned in the next year, focused on the three U.S. Department of Energy Bioenergy Research Centers (Great Lakes Bioenergy Research Center, BioEnergy Science Center, and Joint BioEnergy Institute), and emerging technologies for biodiesel production. The purpose of these

M. D. Casler

U.S. Department of Agriculture, Agricultural Research Service,

U.S. Dairy Forage Research Center,

1925 Linden Drive,

Madison, WI 53706, USA

R. Mitchell

U.S. Department of Agriculture, Agricultural Research Service, Grain, Forage, and Bioenergy Research Unit,

University of Nebraska-Lincoln,

314 Biochemistry Hall,

Lincoln, NE 68583, USA

J. Richardson

Poplar Council of Canada,

1876 Saunderson Drive,

Ottawa, ON K1G 2C5, Canada

R. S. Zalesny Jr. ( $\bowtie)$

U.S. Forest Service, Northern Research Station,

Institute for Applied Ecosystem Studies,

5985 Highway K,

Rhinelander, WI 54501, USA

e-mail: rzalesny@fs.fed.us special issues is to highlight emerging research efforts in the areas of biomass, biofuels, and bioenergy. The Short Rotation Crops International Conference represented a unique opportunity for communication and interaction between researchers working on herbaceous and woody bioenergy feedstocks, one that we hope will continue to stimulate new interactions and creative solutions for bioenergy and bioproducts. We invite other groups to submit ideas for future special issues to one of the three co-Editors-inChief of BioEnergy Research.

For quite some time, there has been a substantial need for an international conference integrating biological and social aspects of producing both herbaceous and woody crops for biofuels, bioenergy, and bioproducts. Increasing energy prices worldwide have made alternative sources economically feasible in recent times. Therefore, given substantial support from 26 sponsors representing both agricultural and forestry sectors, the Short Rotation Crops International Conference: Biofuels, Bioenergy, and Bioproducts from Sustainable Agricultural and Forest Crops was held in Bloomington, Minnesota during August 2008. This meeting combined world-leaders in herbaceous and woody biomass energy crops to present more than 90 papers on the state-of-the-art in sustainable energy production and policy. The conference goal was to create an international forum to strengthen old collaborations and create new partnerships to attack some of the pressing issues facing the world's demand for energy. This special issue represents many of the extensive efforts underway to help understand these issues. We hope this collection will help to spark further conversations among scientists, academicians, regulators, and the general public. We encourage you to contact the authors to cultivate such discussions. 
Conference presentations covered a broad range of topics, including anatomy, breeding, genetics, physiology, ecosystem services, phytotechnologies, and production systems, as well as conversion technologies, costs and operational feasibility, environmental impacts and review, social factors, policy issues, and regional logistics. This special issue contains seven papers from the topic areas of breeding and genetics (Gruenewald et al., Zalesny-Ron et al.), woody (Schroeder et al.) and herbaceous (Rock et al.) production systems, costs and operational feasibility (Eisenbies et al.), and phytotechnologies (Zalesny-Jill et al., Witters et al.).

Gruenewald et al. describe the results of four experiments established in the post-mining landscape of the Lusatian lignite-mining district (Brandenburg, northeast Germany) that were established to test the biomass production of Robinia pseudoacacia L. (black locust) in energy plantations. Zalesny (Ron) et al. highlight biomass potential and genotype $\times$ environment interactions affecting growth and development of Populus species and hybrids grown in a network of regional field testing trials in the Midwest USA. Schroeder et al. report fuel and combustion characteristics of four different species (Salix bebbiana Sarg., S. petiolaris Sm., S. eriocephala Michx. and $S$. discolor Mühl) from natural willow rings in
Saskatchewan, Canada following mechanical biomass cutting with a prototype modified agricultural round baler (i.e., Bio-Baler). Rock et al. describe the effect of growth environment on biomass yield, cellulosic ethanol traits, and paper pulp fiber characteristics of Medicago sativa L. (alfalfa) stems across landscape positions (summit and mild slope), seasons of harvest (four harvests per season), and multiple years (2005 and 2006) in Minnesota, USA. Eisenbies et al. review existing studies to estimate quantities of coarse woody residual materials that may be available as a source of bioenergy or biomaterials following harvest of U.S. southern pine forests and whether such removals were sustainable for soil nutrient cycling and other ecosystem functions. Zalesny (Jill) et al. highlight differences in root system morphology that are necessary for enhancing establishment of Populus energy crop production systems in the Midwest USA and similar regions in using wastewaters as irrigation and fertilization for the trees. Witters et al. compare short rotation coppice of Salix with rapeseed and energy maize for metal accumulation capacity (i.e., phytoremediation potential), gross agricultural income per hectare, $\mathrm{CO}_{2}$ emission avoidance potential, and agricultural acceptance throughout the Campine region of Belgium that is contaminated with substantial quantities of cadmium, lead, and zinc. 